\title{
Combined Mathematical Modeling of Different Transport Networks, Considerations and Complex Analysis
}

\author{
Tamás Péter ${ }^{1}$ and Krisztián Szabó ${ }^{2}$ \\ ${ }^{1}$ Department of Control for Transportation and Vehicle Systems, Budapest \\ University of Technology and Economics; Stoczek u. 2, H-1111 Budapest, \\ Hungary; peter.tamas@mail.bme.hu \\ ${ }^{2}$ Institute for Computer Science and Control, Hungarian Academy of Sciences, \\ Kende u. 13-17, H-1111 Budapest, Hungary; szabo.krisztian@sztaki.mta.hu
}

\begin{abstract}
On the grounds of our traffic network model developments an exact mathematical model can be created based on the union of different types of transport networks. The initial network is the vehicle traffic network that integrates the public transport network as well. During this study the union of road and pedestrian networks is initially created and then we further examine the possibility of generalization of complex networks thereafter.
\end{abstract}

Keywords: transport processes; network union model; analysis of movements on mixed trajectories; smart city

\section{Introduction}

The traffic simulations based on traditional methods start out from trip recording (I) or from classical traffic counting methods (II).

(I) With the first type of modeling we talk generally about traffic generation, traffic distribution and traffic sharing, which is expressed in the form of "from/to matrices". This assessment/forecasting method requires very careful circumspection, as it must be representative, while performing an adequate number of survey according to the representativity can be extremely expensive.

In urban districts modeling many models are known (Lill's law of travel, Stouffer's hypothesis, Detroit method, Fratar method, Furness method, Voorhees model, Intervening Opportunity Model, Competing Opportunities Model, multiple regression model, travel cost model, electrostatic model, other synthetic models) which operate with difficult or impossible to measure growth factors, indexes, empirical exponents, etc. 
The input parameters of modeling, therefore, can only be regarded as a benchmark in many cases, thus the product of the simulation can only be considered with the respective significance.

(II) The second type of models are based on junction or cross-sectional traffic counts which employ well-defined methods fixed in road standards and are generally considered to be recognized during transport planning as well. The traffic count is performed according to vehicle types which are expressed in unit vehicle and weighted by multiplication factors.

All these should be carried out at different times of the day in a seasonal manner upon which the daily vehicle traffic, design hour traffic volume, day and night traffic can be calculated $[1,3]$. The advantage of simulation software operating with this type of traffic counts is that the input values determined with reasonable certainty may be accompanied by results of appropriate quality which are well understood by the profession [5]. However, the drawback systems using traffic counts is that the relationship between traffic volume, average speed and vehicle density will not give a clear assignment, e.g. several average speed values can be assigned to a certain traffic volume. The system thus carries uncertainties since, traditional cross-sectional or junction traffic counting methods involve information loss.

\section{The Approach and Methodology used in our Traffic Network Model Developments}

A passenger often travels along a complex trajectory during a trip [21]. This condition occurs when the route consists of trajectories from multiple traffic network parts, e.g. in urban traffic the employed bicycle, pedestrian, road and rail traffic trajectories can alter freely according to the needs in the most appropriate way. Of course, this is not only typical of urban transport. Each compound trip takes place on a complex trajectory, which can include, in addition to the above, water and air transport as well.

The choice of a complex trajectory is always a solution of a conditional optimum problem of certain quality, considering the possibilities and travelers' goals. The mixed trajectories play an important role in the modeling of optimal arrivals and in the load and reliability analysis of the complex traffic networks as, well.

The different dynamic traffic network systems operate in parallel following mainly the laws of their own and their control. Their operations are also, effected by the external environmental and meteorological processes [7, 16, 23].

However, the state parameters of these systems have a mutual impact on each other and influence each other's traffic processes as well. 
All of these complex relationships justify the examination of the union of different dynamic traffic network systems and the actuality of the topic.

The dynamic network and any of its trajectories in our study has two basic characteristics: the map graph is the geometrical characteristics and the type of the flowing "material" is the dynamic characteristics. If for two dynamic networks - in the case of this study two transport networks - the two graphs are identical, but the type of the flowing "material" is different we consider them different disjoint dynamic networks. This could be for example the case of a shared pedestrian-bicycle path that can be used by pedestrians and bicycles together, or a public traffic lane used by trams and buses together. In our modeling, therefore, all types of dynamic models describe their own flow. If another flow is present either on the sections, or even as a crossing movement, its state parameters are taken into account in the influence, inhibition and transfer prohibition functions of the model.

The unified network graph is analyzed for different modes of transport. Because of the novelty of the approach it is particularly interesting from the pedestrian and vehicle traffic point of view. The pedestrian traffic graph is also divided into sectors according to our vehicle traffic network model development, on which the passenger facilities of public transport, the intersections with the vehicle network, taxi and shared mobility (car-sharing, bike-sharing) stations create additional disposition points.

The road traffic network model in this study includes the surface public transport network as well. Their joint operation takes place according to the laws of a large macroscopic model. The pedestrian traffic, also, uses this in the unified model "assembly line".

The vehicle traffic network models are to some extent autonomous dynamic macroscopic systems in the large network, based on their own speed-density, control laws. At the same time, the integration with the pedestrian system results in the entry of new dynamics and conditions in its operation as well, e.g. during rush hours, the time spent at stops by public transport vehicles and the dynamics of the vehicles changes.

The pedestrian traffic network model provides more advanced features as well. In case of pedestrians the laws of speed-density functions show up relatively rarely along their own route, but at congestion points they should be considered.

Based on the developed model [6], the optimal network paths, trajectories can be determined. It can be transmitted also to the discussed complex network model. 


\subsection{Motivations}

One of the biggest challenges in the modeling is the alignment of various modes of transport and the mapping of processes of method and vehicle changing points.

The developed new approach was motivated by several basic issues that can no longer be ignored while using ITS network models. The research gives a new direction of targeted basic research in the field of transportation in connection with priority industries [21].

The use of traditional modeling approach raises several unanswered questions and constantly struggles with size problems.

All subnetwork is different, there is a wide variety of specific rules, in this context, studying any part of the network by itself is only a very small part of the whole and it can be only an example taken from the large network.

If only software algorithmic models are used, they are not suited to give a wider range of exact mathematical conclusions and results.

In traditional models the role of the parking places is a problem [22], since they are different types of actors than road sections, so-called foreign elements with "storage properties".

The complexity of the transport processes requires the application of a high-level of automation and intelligent transport systems (ITS), the common basis of which are the transport models $[25,26,27,28]$.

Our new vehicle traffic network model is macroscopic and map graph invariant, it can be described with a special hyper-matrix structure [17]. Its main strengths are the uniformization of the very complex network and the high computing speed.

\subsection{The Applied New Model}

There are four kinds of connections between the examined internal and the surrounding external network sectors. The dynamic operation (internal and external) of the entire network is systematized by the connection hyper-matrix. The connection hyper-matrix provides information on any sector in terms of with which other sectors are they connected by what kind of dynamic transfer. The system of differential equations containing the connection hyper-matrix describes the operation of all sectors of the network that means the operation of the entire network $[18,20]$.

Our macroscopic model, which describes the transport processes on large-scale road networks, belongs to the class of positive nonlinear systems. The model is suitable for simulation test of large-scale road networks, planning and traffic control systems [19]. 


$$
\left[\begin{array}{c}
\dot{x} \\
\dot{s}
\end{array}\right]=\left[\begin{array}{ll}
\langle L\rangle^{-1} & \\
& \langle P\rangle^{-1}
\end{array}\right]\left[\begin{array}{ll}
K_{11}(x, s) & K_{12}(x, s) \\
K_{21}(x, s) & K_{22}(x, s)
\end{array}\right]\left[\begin{array}{l}
x \\
s
\end{array}\right]
$$

In our model we apply $0 \leq \mathrm{x}(\mathrm{t}) \leq 1$ and $0 \leq \mathrm{s}(\mathrm{t}) \leq 1$ normalized vehicle density state parameters.

$x \in \mathfrak{R}^{\mathrm{n}}$ is the state parameter vector of internal sectors,

$s \in \mathfrak{R}^{\mathrm{m}}$ is the state parameter vector of external sectors,

$\dot{x} \in \mathfrak{R}^{n}$ is the time derivative of the state parameter vector of internal sectors,

$\dot{S} \in \mathfrak{R}^{m}$ is the time derivative of the state parameter vector of external sectors,

$\langle L\rangle$ and $\langle P\rangle$ are diagonal matrices containing the length of internal and external sectors, respectively:

$$
\langle L\rangle=\left\langle l_{1}, l_{2}, \ldots, l_{n}\right\rangle,\langle P\rangle=\left\langle p_{1}, p_{2}, \ldots, p_{m}\right\rangle
$$

The submatrices of $\mathrm{K}$ connection hyper-matrix are:

$K_{11} \in \mathfrak{R}^{\mathrm{nxn}}, K_{12} \in \mathfrak{R}^{\mathrm{nxm}}, K_{2 l} \in \mathfrak{R}^{\mathrm{mxn}}, K_{22} \in \mathfrak{R}^{\mathrm{mxm}}$ és $x \in \mathfrak{R}^{\mathrm{n}}, s \in \mathfrak{R}^{\mathrm{m}}$.

The elements of the matrices are $v_{\mathrm{ij}}$ connection speeds which are created as the product of the following seven connection functions:

$$
v_{\mathrm{ij}}=\alpha_{\mathrm{ij}} \beta_{\mathrm{ij}} \gamma_{\mathrm{ij}} \mathrm{u}_{\mathrm{ij}}(\mathrm{t}) S\left(\mathrm{x}_{\mathrm{i}}(\mathrm{t})\right) V_{\mathrm{ij}}\left(\mathrm{x}_{\mathrm{i}}(\mathrm{t}), \mathrm{x}_{\mathrm{j}}(\mathrm{t}), \underline{e}_{i}, \underline{e}_{j}\right) E\left(\mathrm{x}_{\mathrm{j}}(\mathrm{t})\right)
$$

In case of the above product at $j \AA i$ connection $\alpha_{\mathrm{ij}}=\alpha_{\mathrm{ij}}(\underline{\mathbf{x}}(\mathrm{t}), \mathrm{t})$ means distribution, $\beta_{\mathrm{ij}}=\beta_{\mathrm{ij}}(\underline{\mathbf{x}}(\mathrm{t}), \mathrm{t})$ is a factor obstructing or supporting the connection, $\gamma_{\mathrm{ij}}=\gamma_{\mathrm{ij}}(\mathrm{t})$ denotes the intensity of the connection and $\mathrm{u}_{\mathrm{ij}}(\mathrm{t})$ the traffic light signal, which are non-negative dimensionless values.

$S$ and $E$ are internal prohibiting automation functions acting at the connections.

$\mathrm{S}(x)$ is an automatic internal self-control function that takes the value 1 or 0 . The connection is permitted if the density of the receiving section $\mathrm{x}$ is less than 1 , otherwise it is prohibited.

$\mathrm{E}(x)$ is an automatic internal self-control function that takes the value 1 or 0 . The connection is prohibited if the density of the transmitting section $\mathrm{x}$ is less than or equals 0 , otherwise it is permitted.

$V_{\mathrm{ij}}$ is the transfer speed $[\mathrm{m} / \mathrm{s}]$, which at time t depends on the state parameters of the connected sections and on $\underline{e}_{i}, \underline{e}_{j}$ environmental parameter vectors of sections $\mathrm{i}$ and $\mathrm{j}$.

Based on this the elements of the connection matrix are speed values $[\mathrm{m} / \mathrm{s}]$. 
The values in the main diagonal of $K_{11}$ and $K_{22}$ are 0 or negative, all other elements take non-negative values. All elements of $K_{12}$ and $K_{21}$ take non-negative values. These matrices are, therefore, Metzler matrices, consequently the $K$ connection hyper-matrix defined by them that describes the entire connection system is a Metzler matrix as well [2,8].

Our macroscopic model of transport processes on large-scale road networks belongs to the class of positive nonlinear systems.

\subsection{Mathematical Model of the Narrowed Traffic Network}

The narrowed network model consists of an internal network of $\mathrm{n}$ sectors bounded by an arbitrary closed curve „G” and m external sectors with densities $s_{1}, s_{2}, \ldots$, $s_{\mathrm{m}}$, which have direct connections with an internal sector, the state of which is considered as known based on measurements. In this model among the matrices forming the connection hyper-matrix only $K_{11}$ and $K_{12}$ matrices play a role because they represent every transfer with relation to the internal sectors. (The external-external connections are not considered in this case). The system of differential equations of the model is the following:

$$
\dot{x}=<L>^{-1}\left[K_{11}(x, s) x+K_{12}(x, s) s\right]
$$

Where: $x \in \mathfrak{R}^{\mathrm{n}}, \forall \mathrm{x}_{\mathrm{i}} \in[0,1],(\mathrm{i}=1,2, \ldots, \mathrm{n}), \dot{x} \in \mathfrak{R}^{n}, \mathrm{~s} \in \mathfrak{R}^{\mathrm{m}}, \forall \mathrm{s}_{\mathrm{i}} \in[0,1],(\mathrm{i}=1,2, \ldots, \mathrm{m})$, $L=\operatorname{diag}\left\{1_{1}, \ldots, 1_{\mathrm{n}}\right\}, 1_{\mathrm{i}}$ the length of internal sections in the main diagonal $\left(\forall \mathrm{l}_{\mathrm{i}}>0\right.$, $\mathrm{i}=1,2, \ldots, \mathrm{n}), K_{11} \in \mathfrak{R}^{\mathrm{nxn}}, K_{12} \in \mathfrak{R}^{\mathrm{nxm}}$. 


\section{The Union of Vehicle and Pedestrian Traffic Network Models}

\section{The relations of Inner $\left(\mathrm{H}_{\mathrm{B}}\right)$ and Outer $\left(\mathrm{H}_{\mathrm{K}}\right)$ network}

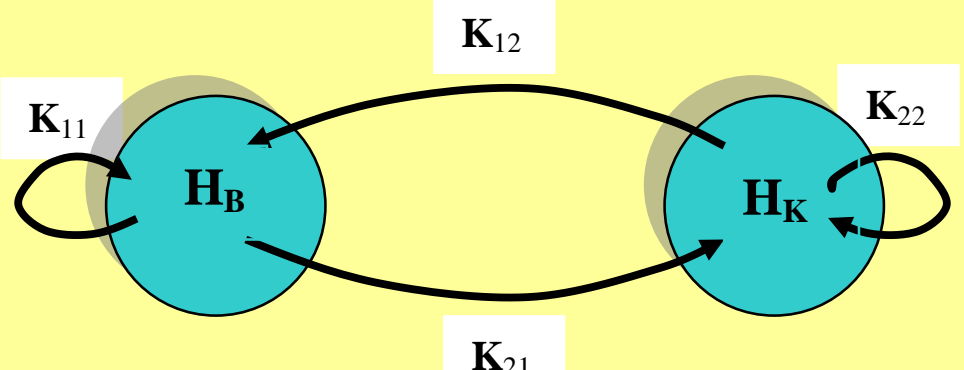

$\mathbf{K}_{21}$

Figure 1

Connections of internal and external networks in case of road traffic

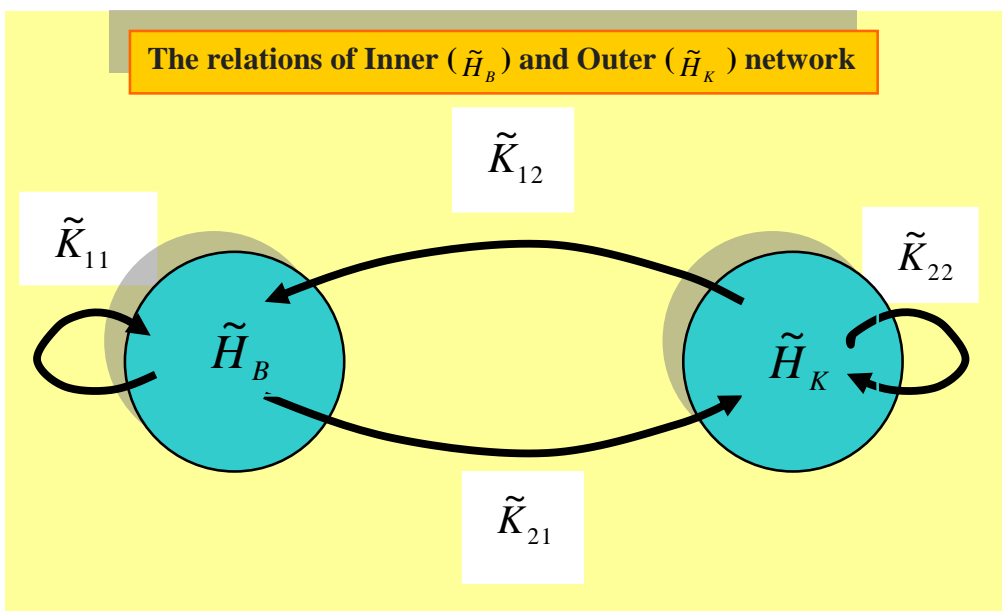

Figure 2

Connections of internal and external networks in case of pedestrian traffic

The developed and used road traffic model examined primarily the vehicle processes. This model is a macroscopic model with arbitrary network dimension.

We show that the model can be extended with appropriate considerations to pedestrian traffic network modeling and analysis of movements and speed processes of pedestrians on the network as well [21]. 
It must be emphasized that although the organizational structure of pedestrian traffic network model and road traffic model is identical, but the two models form a disjoint network.

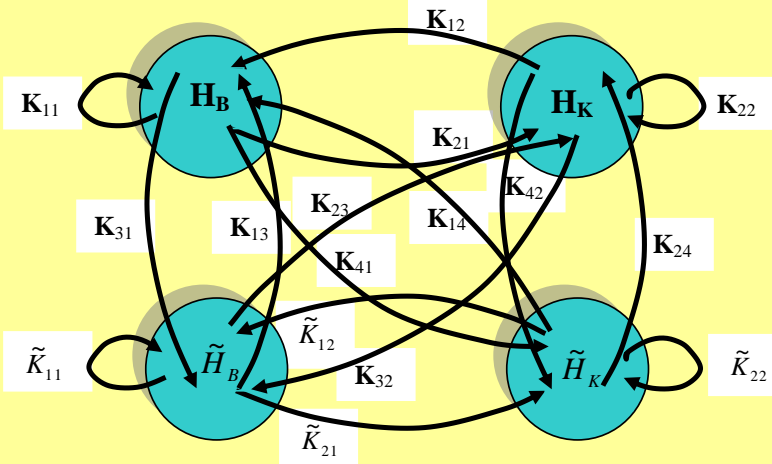

Figure 3

Hyper-network connection system of road and pedestrian traffic

The hyper-matrix describing the entire connection system of the union of vehicle and pedestrian traffic network models is the following:

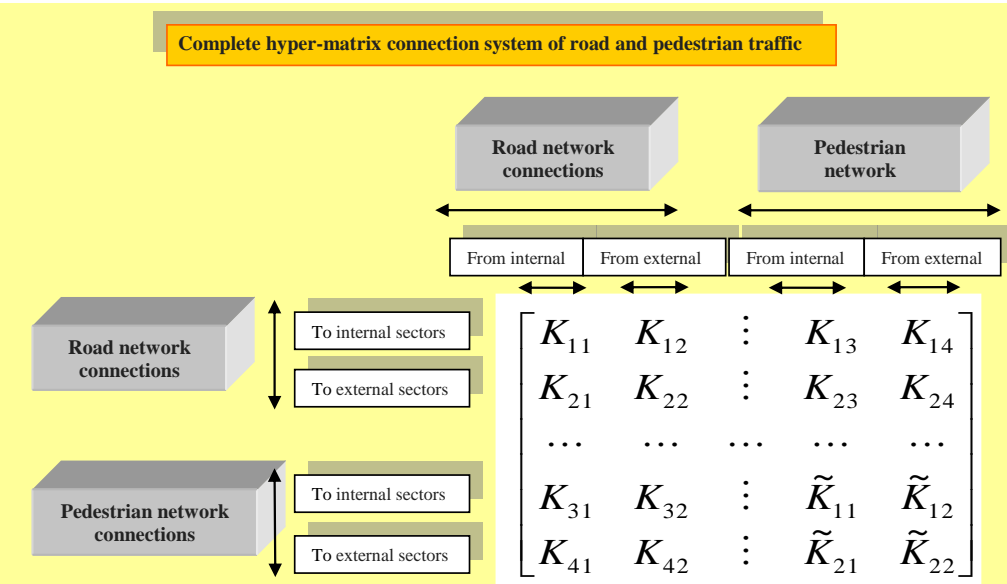

Figure 4

The hyper-matrix describing the entire connection system of road and pedestrian traffic 
In the union of the two networks the mathematical modeling applies the following hyper-matrix in the system of differential equations:

$$
K=\left[\begin{array}{ccccc}
K_{11} & K_{12} & \vdots & K_{13} & K_{14} \\
K_{21} & K_{22} & \vdots & K_{23} & K_{24} \\
\cdots & \cdots & \cdots & \cdots & \cdots \\
K_{31} & K_{32} & \vdots & \tilde{K}_{11} & \tilde{K}_{12} \\
K_{41} & K_{42} & \vdots & \tilde{K}_{21} & \tilde{K}_{22}
\end{array}\right]
$$

During the modeling a closed domain is analyzed (the so called narrowed model is used) and traffic on the edges are considered on the basis of measurement results, so all external-external relations,

e.g. $K_{22}, \tilde{K}_{22}$ are not needed to be analyzed.

The union of these two models means that the two networks establish close dynamic connections with each other and the existing ones are complemented with new internal-internal, external-internal, and internal-external connections.

Narrowed hyper-network connection system of road and pedestrian

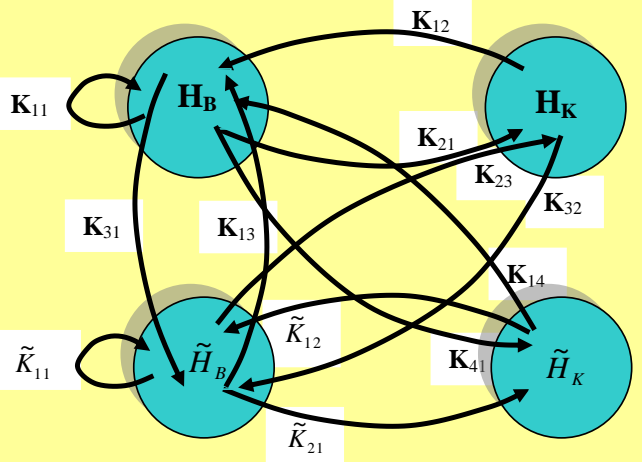

Figure 5

Narrowed connection system of road and pedestrian traffic hyper-network

The hyper-matrix describing the narrowed connection system of the union of vehicle and pedestrian traffic network models is the following: 


$$
K=\left[\begin{array}{ccccc}
K_{11} & K_{12} & \vdots & K_{13} & K_{14} \\
K_{21} & 0 & \vdots & K_{23} & 0 \\
\cdots & \cdots & \cdots & \cdots & \cdots \\
K_{31} & K_{32} & \vdots & \tilde{K}_{11} & \tilde{K}_{12} \\
K_{41} & 0 & \vdots & \tilde{K}_{21} & 0
\end{array}\right]
$$

\subsection{Remarks on the Union of Network Models}

1) The union operation is mathematically closed because the same macroscopic approach is applied to pedestrian traffic and road vehicle traffic. The mathematical model of both dynamic networks is a Euler model belonging to the positive nonlinear system class. Further generalization is the union of several physically different - but according to the above - mathematically identical network models. Since they are disjoint, we can perform the extension of base networks practically in a serial recursive manner, and thus the base network is replaced by the extended one.

The structure of the model in this case is the following: the top left corner of the main diagonal of the new connection hyper-matrix contains the base network while the sub matrix in bottom right corner of that represents the additional network (both with the entire internal-internal, input and output connections). The transport connections from the new network towards the base network are entered in the top right corner of the antidiagonal of the new connection hyper-matrix, while those from the base network towards the new network are in the bottom left corner of the antidiagonal.

So technically the extension is always the filling of the antidiagonal, which considers the connections between the two networks.

Any changes that can be transferred into these new network parts corresponding to the road model features must be defined at the elements of the connection matrices.

The union related to public transport network in case of buses and trolleys can be handled easier than the one related to pedestrian and cycling network. The macroscopic flow modeling of tram, subway, suburban railway and railway traffic is well manageable with the scheduled stopping of the flow at stops, similarly to the traffic light control method. The validation of the model can be performed with the analysis of speed processes and travel times.

2) An important characteristic of the union is that it is created through a dynamic co-operation of physically separate networks. It can be concluded that some networks keep their internal autonomy, while at the same time they have a high level of co-operation with each other. 
3) The pedestrian traffic network has two types of edge connection, on the one hand the inputs and outputs originating from the external pedestrian network connections and on the other hand those from the road network element connections by the union.

4) The input-output connections of the road network are not changed by the union, they invariably receive and transfer vehicle flow. The time delays in the vehicle traffic network, however, can be greatly affected by the state parameter vector $\tilde{\mathbf{x}^{\sim}}$ of the pedestrian density that occurs at pedestrian crossings and in the case of passenger exchange stop times of community vehicles which are taken into account in the model by the $\beta_{\mathrm{ij}}\left(\underline{\mathbf{x}}^{\sim}\right)$ pedestrian state-based obstruction factors. In some overload cases the speed reductions due to the change in acceleration capabilities of the vehicles emerge at the speed-density law, taking into account the pedestrian state parameter vector $\mathrm{V}(\underline{\mathbf{x}}, \underline{\mathbf{x}}, \underline{\mathbf{e}})$.

5) A common property of both networks is that state and time-dependent flow distribution is created at each junction. This property can be recorded and measured with cameras. At the macroscopic modeling the personal expectations and preferences of the travelers prevail through the distributions. However, another, better traffic control may change the distributions in the same time of the day.

6) The transfer processes between the section elements are disturbed by traffic lights and obstructed or supported by the state-dependent transfer factors, the transfer speeds are affected by the state and environmental factors.

7) The "system control" in respect of "traveler influence" can be studied optimizing the passes through the union of two networks (speed/time, cost, environmental load) [12]. The analysis of the passes of pedestrians between selected pairs of points on the network on mixed trajectories is performed in "traveler stream" manner (with mixed-use of pedestrian road sections and community vehicles) it is practical to give strategies for the determination of the selected pairs of points. The control strategy should be formulated as a model predictive control MPC-based one with a model computing time orders of magnitude faster than the real time, of which our mathematical model is capable.

If the optimal arrival is analyzed on multiple trajectories, task requires the solution of a variational computational problem. Along all trajectories the $\mathrm{X}$ length of the road travelled to $t$ time leads to an $\mathrm{X}(\mathrm{t})$ route function that gives $T$ travel time upon arrival at point " $\mathrm{B}$ " and this mapping provides the real function $\mathrm{J}$ :

$\mathrm{J}: X(\mathrm{t}) \rightarrow T$

The model describing the large-scale transport networks thus can be applied in real time route recommendation taking into account the traffic parameters as well. 


\section{Example for the Union of Vehicle and Pedestrian Traffic Models}

\subsection{Description of the Example Model}

The solid lines indicate the road network, the dashed lines indicate the pedestrian network. The input and output connections of both are denoted by dual-line arrows.

The tilde-marked section numbering and input-output points relate to pedestrian traffic. The standard section numbering and input-output points relate to road traffic. $\mathbf{T}_{1}$ and $\mathbf{T}_{2}$ transits between pedestrian and road traffic.

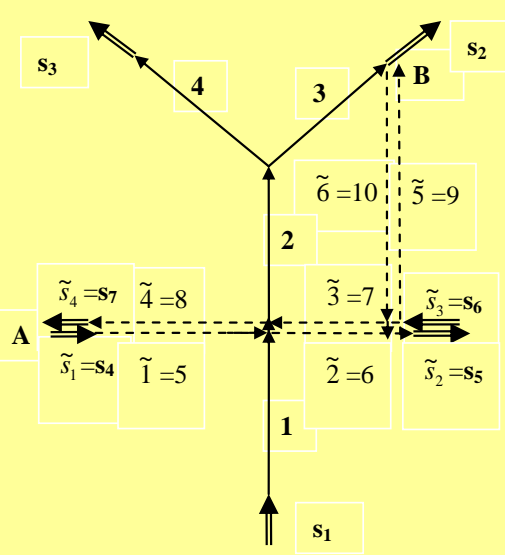

Figure 6

Simple example of road and pedestrian network connections

The relationship between the two networks is characterized by the following:

$\underline{\text { Road traffic influencing observed: }}$

The road traffic between 1 and 2 is obstructed by the pedestrian traffic of sections $2^{\sim}$ and $4^{\sim}$ passing across the junction through the marked pedestrian crossing, which is considered with the pedestrian density.

The distributions acting at pedestrian traffic:

$3^{\sim}$ to $4^{\sim}$ and $3^{\sim}{ }^{\circledR}$ to 2 .

$1^{\sim}$ ๑ to $2^{\sim}$ and $1^{\sim} \otimes$ to 2.

$6^{\sim} \oplus$ to $3^{\sim}$ and $6^{\sim} \otimes$ to $\tilde{s}_{2}$.

$2^{\sim} \otimes$ to $5^{\sim}$ and $2^{\sim} \otimes$ to $\mathrm{s}_{2}$.

$\tilde{\mathrm{s}}_{3}{ }^{\oplus}$ to $5^{\sim}$ and $\tilde{s}_{3}$ बto $3 \sim$. 
The distributions acting at road traffic:

$2{ }^{\oplus}$ to 3 and $2 \otimes$ to 4 .

$3 \oplus$ to $s_{2}$ and $3 \oplus$ to 6 .

\subsection{The Computer-Algebraic Mathematical Model of the Example Model}

The analysis of the union of vehicle and pedestrian traffic networks. Let us consider the previously discussed connection hyper-matrix describing the entire system of connections: Figure 4.

In the example model the following matrices are zero matrices:

- Since there are no external-external connections within the own network $\mathrm{K}_{22}=0$, $\mathrm{K}_{22}^{\sim}=0$.

- Since there are no connections from external pedestrian networks to road networks $\mathrm{K}_{14}=0, \mathrm{~K}_{24}=0$.

- Since there are no connections from external road networks to pedestrian networks $\mathrm{K}_{32}=0, \mathrm{~K}_{42}=0$.

- Since there are no connections from internal road network to external pedestrian networks $\mathrm{K}_{41}=0$.

Based on the above, the following sub-matrices of the connection hyper-matrix describe the connection system of the network union:

$$
K=\left[\begin{array}{ccccc}
K_{11} & K_{12} & \vdots & K_{13} & 0 \\
K_{21} & 0 & \vdots & K_{23} & 0 \\
\cdots & \cdots & \cdots & \cdots & \cdots \\
K_{31} & 0 & \vdots & \tilde{K}_{11} & \tilde{K}_{12} \\
K_{41} & 0 & \vdots & \tilde{K}_{21} & 0
\end{array}\right]
$$

Using the narrowed network model described based on the system of differential equation (2) the construction of submatrices was carried out using a computeralgebraic model. The symbols used in the following are found in section 2.2 , at the description of the mathematical model of universal vehicle traffic network.

For the description of the road network model the following matrices were determined:

$\mathbf{K}_{11}$ : 


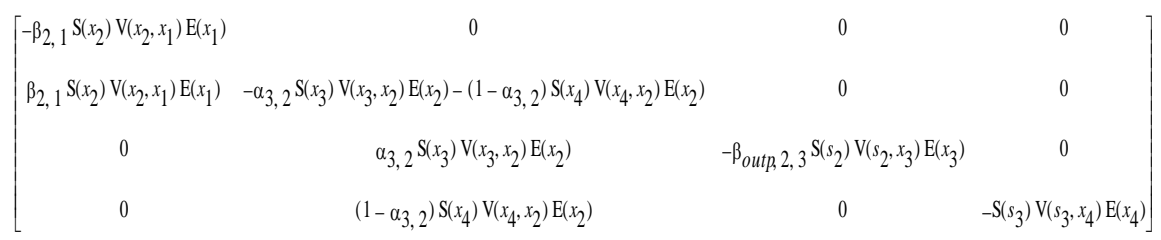

In the example model the road traffic obstruction by the pedestrian traffic occurs at the marked pedestrian crossing at $\mathrm{T}_{1}$ taking into account the pedestrian density with the function $\beta_{2,1}\left(\tilde{x}_{2}, \tilde{x}_{4}\right)$.

$\mathbf{K}_{12}$ :

$$
\left[\begin{array}{ccc}
\beta_{\text {inp }, 1,1} \mathrm{~S}\left(x_{1}\right) \mathrm{V}\left(x_{1}, s_{1}\right) \mathrm{E}\left(s_{1}\right) & 0 & 0 \\
0 & 0 & 0 \\
0 & 0 & 0 \\
0 & 0 & 0
\end{array}\right]
$$

For the description of the pedestrian network model the following matrices are applied:

$\mathbf{K}_{11}^{\sim}$ :

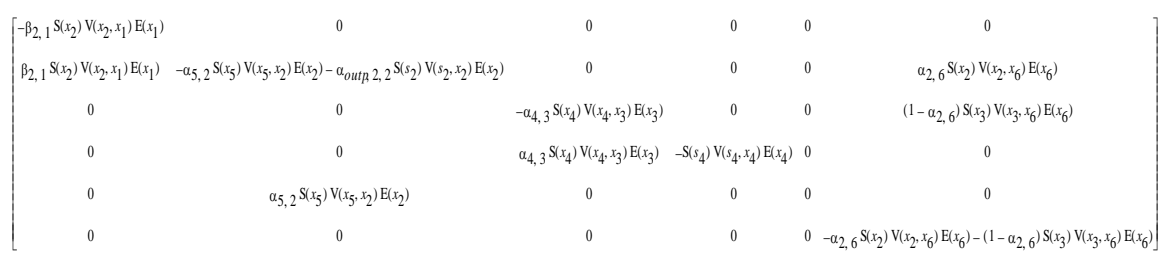

$\mathbf{K}_{12}^{\sim}$ :

$$
\left[\begin{array}{cccr}
\mathrm{S}\left(x_{1}\right) \mathrm{V}\left(x_{1}, s_{1}\right) \mathrm{E}\left(s_{1}\right) & 0 & 0 & 0 \\
0 & 0 & 0 & 0 \\
0 & 0 & \alpha_{i n p, 3,3} \mathrm{~S}\left(x_{3}\right) \mathrm{V}\left(x_{3}, s_{3}\right) \mathrm{E}\left(s_{3}\right) & 0 \\
0 & 0 & 0 & 0 \\
0 & 0 & \left(1-\alpha_{i n p, 3,3}\right) \mathrm{S}\left(x_{5}\right) \mathrm{V}\left(x_{5}, s_{3}\right) \mathrm{E}\left(s_{3}\right) & 0 \\
0 & 0 & 0 & 0
\end{array}\right]
$$

The amounts to be transferred from the pedestrian traffic to the vehicles, e.g. the one at point $\mathbf{T}_{\mathbf{1}}$ from sections $1^{\sim}$ and $3^{\sim}$ obviously only reduces the density of pedestrian traffic, but does not increase the vehicle density. Similarly, the passengers getting off at point $\mathbf{T}_{\mathbf{2}}$ do not reduce the vehicle density, but increase the pedestrian density on section $6^{\sim}$. In the case of section $5^{\sim}$ one can see that there is a pedestrian flow to an external road network section. 
However, the pedestrians on vehicles ("temporary" passengers) are periodically removed from pedestrian traffic, in this way they play the same role as the parking places on the road traffic network. It is special in the way that they are staying on moving "parking places".

The pedestrian traffic getting on at point $\mathbf{T}_{\mathbf{1}}$ and likewise getting on or off at point $\mathbf{T}_{2}$ can be controlled by the schedule-adjusted $\gamma_{\mathrm{i}}(\mathrm{t})$ intensity functions.

\section{Generalization of the Problem}

The generalization of the problem in the case of surface traffic networks is the determination of the union of $\mathrm{n}$ different types of disjoint traffic networks. This results in a joint system model, which considers co-operations existing in the real world. The general approach can be illustrated well with $n=4$ different types of disjoint traffic networks.

Let us consider the following network types:

$\mathrm{H}_{\mathrm{K}}$ : road network

$\mathrm{H}_{\mathrm{G}}$ : pedestrian network

$\mathrm{H}_{\mathrm{P}}$ : rail network

$\mathrm{H}_{\mathrm{B}}$ : bicycle network

According to the above in addition to the previously considered road vehicle and pedestrian processes rail and bicycle network processes are taken into account as well.

In the creation of the union of various disjoint traffic network systems a more complex case can occur than the model type used in practice (the cases allowing multiple connections), because in this case internal and external networks (which generate the input and output processes) belongs to each network type (the state parameters of which are studied).

The main diagonal (the colored matrices) of the connection hyper-matrix of the combined network (the union) contains the connection hyper-matrices of the different sub-networks.

The mathematical model contains $\mathrm{n}^{2}-\mathrm{n}$ connection hyper-matrices outside the main diagonal, since in principle any internal element of a network can be in connection with internal or external elements of a different network. Similarly, any external element of a network can be in connection with internal or external elements of a different network. These are the connections outside the main diagonal of the hyper-matrix. In the example these are illustrated by the arrows. 


\begin{tabular}{|c|c|c|c|c|c|c|c|c|c|}
\hline & \multicolumn{2}{|c|}{$\mathbf{H}_{\mathbf{K}}$} & \multicolumn{2}{|c|}{$\mathbf{H}_{\mathbf{G}}$} & \multicolumn{2}{|c|}{$\mathbf{H}_{\mathbf{P}}$} & \multicolumn{2}{|c|}{$\mathbf{H}_{\mathbf{B}}$} \\
\hline & & Inner & Outer & Inner & Outer & Inner & Outer & Inner & Outer \\
\hline \multirow[t]{2}{*}{$\mathbf{H}_{\mathbf{K}}$} & Inner & & & & & & & & \\
\hline & Outer & & & & & & & & \\
\hline \multirow[t]{2}{*}{$\mathbf{H}_{\mathbf{G}}$} & Inner & 4 & & & & & & & \\
\hline & Outer & & & & & & & & \\
\hline \multirow[t]{2}{*}{$\mathbf{H}_{\mathbf{P}}$} & Inner & & & & & & & & 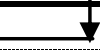 \\
\hline & Outer & 5 & & 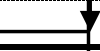 & & & & & \\
\hline \multirow[t]{2}{*}{$\mathbf{H}_{\mathbf{B}}$} & Inner & 4 & & 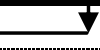 & & & & & \\
\hline & Outer & & & & & & & & \\
\hline
\end{tabular}

Figure 7

The connection hyper-matrix of the union in the case of four different types of disjoint traffic networks

In reality, the physical properties of each network systems are those which, in principle, permit or prohibit the potential cross-connections. The properties related to the cross-connections are presented below for the case of a simpler structure with four different types of global disjoint traffic networks.

The creation of the union of global disjoint traffic network systems is the simpler case, because each network type has only internal networks (the state parameters of which is examined on the entire surface of the Earth) and the external networks are empty networks.

\begin{tabular}{|c|c|c|c|c|}
\hline & $\mathrm{H}_{\mathrm{K}}$ & $\mathrm{H}_{\mathrm{G}}$ & $\mathrm{H}_{\mathrm{P}}$ & $\mathrm{H}_{\mathrm{B}}$ \\
\hline$H_{K}$ & & $\mathrm{~K}_{\mathrm{K}, \mathrm{G}}$ & 0 & $\mathrm{~K}_{\mathrm{K}, \mathrm{B}}$ \\
\hline $\mathrm{H}_{\mathrm{G}}$ & $\mathrm{K}_{\mathrm{G}, \mathrm{K}}$ & ||l|| & $\mathrm{K}_{\mathrm{G}, \mathrm{p}}$ & $\mathrm{K}_{\mathrm{G}, \mathrm{B}}$ \\
\hline $\mathbf{H}_{\mathbf{P}}$ & $\mathrm{K}_{\mathrm{P}, \mathrm{K}}$ & $\mathrm{K}_{\mathrm{P}, \mathrm{G}}$ & (1) & $\mathrm{K}_{\mathrm{P}, \mathrm{B}}$ \\
\hline $\mathrm{H}_{\text {в }}$ & 0 & $\mathrm{~K}_{\mathrm{B}, \mathrm{G}}$ & 0 & \\
\hline
\end{tabular}

Figure 8

The connection hyper-matrix of the union in the case of four different types of global disjoint traffic networks

The properties of the sub-matrices of the connection hyper-matrix are the following:

$\mathrm{K}_{\mathrm{K}, \mathrm{G}}$ : transfers passengers from pedestrian traffic to road traffic, but does not increase the vehicle density of road traffic

$\mathrm{K}_{\mathrm{G}, \mathrm{K}}$ : transfers passengers from road traffic to pedestrian traffic, but does not decrease the vehicle density of road traffic

$\mathrm{K}_{\mathrm{P}, \mathrm{G}}$ : transfers passengers from pedestrian traffic to rail traffic, but does not increase the vehicle density of rail traffic

$\mathrm{K}_{\mathrm{G}, \mathrm{P}}$ : transfers passengers from rail traffic to pedestrian traffic, but does not decrease the vehicle density of rail traffic 
0: rail traffic does not transfer vehicles to road traffic

$\mathrm{K}_{\mathrm{P}, \mathrm{K}}$ : road traffic can transfer vehicles to rail traffic, but it does not increase the vehicle density of rail traffic (e.g. rail transportation of road vehicles)

0: road traffic does not transfer vehicles to bicycle traffic

$\mathrm{K}_{\mathrm{K}, \mathrm{B}}$ : bicycle traffic can transfer vehicles to road traffic. There are two cases: 1) the bicycle effectively takes part in the traffic and increases the density, 2) it is placed on a vehicle without increasing the density. The bicycle network density is decreasing in both cases.

$\mathrm{K}_{\mathrm{B}, \mathrm{G}}$ : transfers passengers from pedestrian traffic to bicycle traffic. The pedestrian density is decreasing; the bicycle density is increasing from the parking bicycles.

$\mathrm{K}_{\mathrm{G}, \mathrm{B}}$ : transfers passengers from bicycle traffic to pedestrian traffic. The density of parking bicycles and the passenger density is increasing as well.

0: rail traffic does not transfer vehicles to bicycle traffic

$\mathrm{K}_{\mathrm{P}, \mathrm{B}}$ : transfers passengers from bicycle traffic to rail traffic, but does not increase the vehicle density of rail traffic (e.g. transportation of bicycles). The density of bicycle traffic is decreasing.

\section{Conclusion}

We presented a new macroscopic mathematical modeling technique based on the union of the models. The model belongs to very new and modern area in the field of mathematical research, as it is located in the non-linear positive system class. The special hyper-matrix structure defines the cooperation of network elements and the system of differential equations describing the connections. These models provide excellent opportunities for the application of the Lyapunov function method in various areas of the domain-level non-linear control as well. The application possibilities in the domain-level control in big cities are significant. The model has excellent capabilities in the optimization of movements along the trajectories and in the reduction of traffic-oriented environmental pollution [11, 24]. The model is particularly suitable for describing the transfer/vehicle exchange processes that are critical elements of transportation chains.

The exploration and the better understanding of processes occurring in large-scale complex traffic networks led us to a new principled modeling and to the introduction of flexible optimal control methods. The purpose of the control can change flexibly based on the different states of the network in different domains. The network ITS is a variable network that evaluates the optimal satisfaction of direct demands related to traffic during the operation, such as optimal arrival, environmental load, safety and power-saving operation [13, 14, 15]. The projects aiming at creating urban traffic models serve for reducing both congestion and environmental impact $[9,10]$. 
The additional software development related to the research aims to provide a tool for real-time industrial control tasks in case of large-scale intelligent road networks. Notably, in every case the preparation of the traffic system plan of the smart city [4] is the primary compass for the implementation of an ITS network. The synergy and the potential for further exploitation of the results are very positive. New accelerated methods can arise for the analysis of complex movements (transportation chains) along the trajectories, the environmental load and safety as well.

\section{References}

[1] Georgia Aifandopoulou, Iraklis Stamos, Glikeria Myrovali, Maria Morfoulaki (2015) Mapping the Opportunities of Rail Transport; a DataDriven Methodology for Capturing Rail Competitiveness at European Level, Period. Polytech. Transp. Eng., Vol. 43, No. 1 (2015) pp. 48-54, DOI: $10.3311 /$ PPtr.7739

[2] Caccetta and Rumchev, (2000) A Survey of Reachability and Controllability for Positive Linear Systems,' Annals of Operations Research, Vol. 98, pp. 101-122, 2000

[3] Yi Cao, Zhongyi Zuo, Huizhi Xu (2014) Analysis of Traffic Conflict Characteristic at Temporary Reversible Lane, Period. Polytech. Transp. Eng., Vol. 42, No. 1 (2014) pp. 73-76, DOI: 10.3311/PPtr.7068

[4] Bálint Csonka, Csaba Csiszár (2016) Service Quality Analysis and Assessment Method for European Carsharing Systems, Period. Polytech. Transp. Eng., Vol. 44, No. 2 (2016) pp. 80-88, DOI: 10.3311/PPtr.8559

[5] Thierry Brenac, Christophe Perrin, Bastien Canu, Joël Magnin, Adrien Canu (2015) Influence of Travelling Speed on the Risk of Injury Accident: a Matched Case-Control Study, Period. Polytech. Transp. Eng., Vol. 43, No. 3 (2015) pp. 129-137, DOI: 10.3311/PPtr.7520

[6] Ákos Dömötörfi, Tamás Péter, Krisztián Szabó (2016) Mathematical Modeling of Automotive Supply Chain Networks, Period. Polytech. Transp. Eng., Vol. 44, No. 3 (2016) pp. 181-186, DOI: 10.3311/PPtr.9544

[7] Domokos Esztergár-Kiss, Zoltán Koppányi, Tamás Lovas (2016) Mobility Mapping Based on a Survey from the City of Berlin, Period. Polytech. Transp. Eng., Vol. 44, No. 1 (2016) pp. 35-41, DOI: 10.3311/PPtr.7587

[8] Farina, L. and Rinaldi, S, (2000) Positive Linear Systems Theory and Applications. John Wiley \&; Sons, Inc.

[9] István Lakatos; Dániel Pup; Dávid Czeglédi: Determination of Power and Torque Curves of Electric Driven Vehicles based on Diagnostic Methods, in ASME, ASME 2015 International Design Engineering Technical Conferences and Computers and Information in Engineering Conference: Mechatronics for Electrical Vehicular Systems. 31 p., Boston, 2015.08.022015.08.05. New York: American Socety of Mechanical Engineers 
(ASME), 2015. Paper DETC2015-46724; V009T07A069. 11 p. 9, (ISBN: 978-0-7918-5719-9)

[10] Adam Titrik; Istvan Lakatos; David Czegledi: Saturation Optimization of Selective Waste Collection Vehicles Based on Real-Time InfoCommunication System, In: ASME (szerk.), ASME 2015 International Design Engineering Technical Conferences and Computers and Information in Engineering Conference: Mechatronics for Electrical Vehicular Systems. 31 p., Boston, 2015.08.02-2015.08.05. New York: American Socety of Mechanical Engineers (ASME) 2015, Paper DETC2015-46720; V009T07A068. 7 p., (ISBN:978-0-7918-5719-9)

[11] István Lakatos; Péter Kőrös; Viktor Nagy: Operation and Applicability Issues of Powertrain Models in Electric Vehicle Development, In: Anon (szerk.), $10^{\text {th }}$ IEEE/ASME International Conference on Mechatronic and Embedded Systems and Applications, Senigallia, 2014.09.10-2014.09.12. (IEEE) New York: IEEE, 2014, Paper CD (ISBN:978-1-4799-2772-2)

[12] Lakatos István: Diagnostic Measurement for the Effective Performance of Motor Vehicles, Acta Polytechnica Hungarica (ISSN: 1785-8860) 10: (3) pp. 239-249 (2013) Engineering (miscellaneous)

[13] István Lakatos; Ferenc Szauter; Dávid Czeglédi: Investigating the Appliance of Aluminum as a Winding Material with High Efficiency Electric Motor, $12^{\text {th }}$ IEEE/ASME International Conference on Mechatronic and Embedded Systems and Applications, Auckland, New-Zealand, 2016.08.29-2016.08.31. New York: IEEE, 2016 Paper 43, DOI: 10.1109/MESA.2016.7587119

[14] Ernő Horváth, Péter Körös, István Lakatos, Péter Dely: Development of Individual Information Technology Systems of Experimental Vehicles, in Szakál Anikó (szerk.) 10 $0^{\text {th }}$ Jubilee IEEE International Symposium on Applied Computational Intelligence and Informatics (SACI 2015), Timisoara, Romania, 2015.05.21-2015.05.23. Budapest: Óbudai Egyetem, 2015, pp. 489-493 (ISBN:978-1-4799-9910-1) IEEE Xplore

[15] István Lakatos, Peter Dely: In-Cylinder Pressure Indication of Internal Combustion Engines for Diagnostic Purposes, In: Anikó Szakál (szerk.) SAMI 2015 - IEEE $13^{\text {th }}$ International Symposium on Applied Machine Intelligence and Informatics, Herlany, Slovakia, 2015.01.22-2015.01.24. Herlany: IEEE Hungary Section, 2015, pp. 37-40 (ISBN:978-1-4799-82202; 978-1-4799-8221-9)

[16] Mohammad Maghrour Zefreh, Ádám Török (2016) Improving Traffic Flow Characteristics by Suppressing Shared Taxis Maneuvers, Period. Polytech. Transp. Eng., Vol. 44, No. 2 (2016) pp. 69-74, DOI: 10.3311/PPtr.8226

[17] Péter, T. (2012) Modeling Nonlinear Road Traffic Networks for Junction Control, International Journal of Applied Mathematics and Computer Science (AMCS), 2012, Vol. 22, No. 3, pp. 723-732, DOI: 10.2478/v1006012-0054-1 
[18] Peter, T. and Szabo, K. (2012) A New Network Model for the Analysis of Air Traffic Networks. Periodica Polytechnica- Transportation Engineeering 40/1 (2012) 39-45 DOI: 10.3311/pp.tr.2012-1.07

[19] Peter, T. Bokor, J. and Strobl, A (2013) Model for the Analysis of Traffic Networks and Traffic Modelling of Györ, pp 167-172, Doi: 0023, IFAC Workshop on Advances in Control and Automation Theory for Transportation Applications (ACATTA 2013) which is to be held in Istanbul, Turkey, 16-17 September 2013, http://www.acatta13.itu.edu.tr/

[20] Péter, T. and Fazekas, S. (2014) Determination of Vehicle Density of Inputs and Outputs and Model Validation for the Analysis of Network Traffic Processes, Periodica Polytechnica, Transportation Engineering Vol. 42, No 1, 2014, pp. 53-61

[21] Péter T., Csiszár Cs., Mándoki P.: Különböző felszíni közlekedési hálózatok forgalmának együttes modellezése és komplex analízise. Közlekedéstudományi Szemle, LXVII. 1, 2017, pp. 16-34

[22] Domokos Esztergár-Kiss, Csaba Csiszár (2016) Multicriteria Analysis of Hungarian Journey Planners, Period. Polytech. Transp. Eng., Vol. 44, No. 2 (2016) pp. 97-104, DOI: 10.3311/PPtr.8570

[23] Renata Stasiak-Betlejewska (2015) Value Engineering Application in the American Transportation Industry, Period. Polytech. Transp. Eng., Vol. 43, No. 4 (2015) pp. 206-210, DOI: 10.3311/PPtr.8448

[24] Szauter, F., Péter, T. and Lakatos, I. (2014) Examinations of Complex Traffic Dynamic Systems and New Analysis, Modeling and Simulation of Electrical Vehicular Systems, $10^{\text {th }}$ IEEE/ASME International Conference on Mechatronic and Embedded Systems and Applications. Senigallia, 1012 Sept. 2014, INSPEC Accession Number: 14701078, pp. 1-5, DOI: 10.1109/MESA.2014.6935613, Print ISBN: 978-1-4799-2772-2

[25] T. Vadvári and P. Várlaki (2015) Identification of Supply Chains Based on Input-Output Data Period. Polytech. Transp. Eng., Vol. 43, No. 3 (2015) pp. 162-167, DOI: 10.3311/PPtr.7931 Online published: 28-04-2015

[26] T. Vadvári, P. Várlaki, Queuing Models and Subspace Identification in Logistics, Acta Technica Jaurinensis, Vol. 8, No. 1, pp. 63-76, 2015, DOI: 10.14513/actatechjaur. v8.nl. 352

[27] P. Várlaki, T. Vadvári, A. Rövid, Identification of Input-Output Models For Supply Chains - Analytical and Intelligent Approaches, in Global Conference on Operations and Supply Chain Management, Bandung, Indonesia, pp. 88-98, March 12-14, 2012, ISBN:978-967-5705-06-9

[28] Máté Zöldy, Ádám Török (2015) Road Transport Liquid Fuel Today and Tomorrow: Literature Overview, Period. Polytech. Transp. Eng., Vol. 43, No. 4 (2015) pp. 172-176, DOI: 10.3311/PPtr.8095 